\title{
Adsorption of Tea Polyphenols using Microporous Starch: A Study of Kinetics, Equilibrium and Thermodynamics
}

\author{
Xianchun $\mathrm{Hu}^{1,2}$ and Xianfeng $\mathrm{Du}{ }^{1, *}$ \\ 1 State Key Laboratory of Tea Plant Biology and Utilization, Anhui Agricultural University, Hefei 230036, \\ China; tea30@163.com \\ 2 College of Horticulture and Gardening, Yangtze University, Jingzhou 434025, China \\ * Correspondence: dxf@ahau.edu.cn; Tel.: +86-551-6578-6965
}

Academic Editor: Hidenori Tanaka

Received: 18 March 2019; Accepted: 9 April 2019; Published: 12 April 2019

\begin{abstract}
Microporous starch (MPS) granules were formed by the partial hydrolysis of starch using $\alpha$-amylase and glucoamylase. Due to its biodegradability and safety, MPS was employed to adsorb tea polyphenols (TPS) based on their microporous characteristics. The influences of solution $\mathrm{pH}$, time, initial concentration and temperature on the adsorptive capacity were investigated. The adsorption kinetics data conformed to the pseudo second-order kinetics model, and the equilibrium adsorption data were well described by the Langmuir isotherm model. According to the fitting of the adsorption isotherm formula, the maximum adsorption capacity of TPS onto MPS at $\mathrm{pH} 6.7$ and $\mathrm{T}=293 \mathrm{~K}$ was approximately $63.1 \mathrm{mg} / \mathrm{g}$. The thermodynamic parameters suggested that the adsorption of TPS onto MPS was spontaneous and exothermic. Fourier transform infrared (FT-IR) analysis and the thermodynamics data were consistent with a physical adsorption mechanism. In addition, MPS-loaded TPS had better stability during long-term storage at ambient temperature.
\end{abstract}

Keywords: microporous starch; adsorption; tea polyphenols; kinetics; isotherm; thermodynamics

\section{Introduction}

Tea polyphenols (TPS) are one of the main active substances in tea leaves [1,2]. Tea polyphenols possess aromatic rings with one or more hydroxyl groups [3], which have been shown to provide significant health benefits, including antioxidant activity, anticancer activity, reducing blood fat, and lowering blood sugar; hence, TPS are widely applicable in cosmetics, clinical applications, drugs, and food [4-7].

Microporous starch (MPS) is prepared by reacting various raw starches with starch hydrolytic enzymes ( $\alpha$-amylase and glucoamylase) at temperatures under the gelatinization point [8-13]. Microporous starch granules have plentiful micro pores expanding inside (hilum) from outside (surface), which allow smaller molecules to enter the holes of the granules [14]. Therefore, microporous starch has remarkable adsorption performance because of its large specific surface area. It can be used as an adsorbent in food, medicine, cosmetics, agriculture and other fields [15-18]. For example, some easily oxidized substances (such as vitamin E, $\beta$-carotene, lycopene, etc.) can be protected efficiently by the adsorption of microporous starch [18].

Tea polyphenols are susceptible to oxidants, light, and heat. Microporous starches having abundant pores that can absorb and protect the TPS. To the best of our knowledge, the effects of the kinetics, isotherm behavior and thermodynamics on the adsorption of tea polyphenols in/on MPS have not been investigated. The evaluation of these parameters would be useful for comprehending the types of adsorption occurring and the adsorption mechanisms [19]. The adsorption kinetics and adsorption 
isotherms are the essential aspects to monitor during the process of adsorption [20]. The thermodynamic parameters, including enthalpy change, entropy change and free energy change, provide profound information on the intrinsic energetic changes that are connected with adsorption [21-23].

The objectives of this study were to prepare a microporous starch adsorbent by modification and to assess the kinetics, isotherms and thermodynamics of TPS adsorption onto MPS. The adsorption rates are assessed with the pseudo first-order, pseudo second-order and Weber and Morris intra-particle diffusion equations. The effect of temperature on the adsorption isotherms is measured, and the thermodynamic parameters of free energy $\left(\Delta \mathrm{G}^{0}\right)$, enthalpy $\left(\Delta \mathrm{H}^{0}\right)$ and entropy $\left(\Delta \mathrm{S}^{0}\right)$ during adsorption at different temperatures are calculated. Kinetic and equilibrium isotherm models were employed to evaluate the rate of adsorption and adsorption capacity as well as to reveal the mechanism of TPS adsorption.

\section{Results and Discussion}

\subsection{Effect of $p H$}

The adsorption behavior of TPS onto MPS may differ due to $\mathrm{pH}$ values. For this reason, experiments were conducted in different solutions ranging from $\mathrm{pH} 3$ to $\mathrm{pH} 8$, see Figure $1 \mathrm{~A}$ (Initial conc. $=1.0 \mathrm{mg} / \mathrm{mL}$, Adsorption time $=150 \mathrm{~min}$ ). The $\mathrm{pH}$ of the mixture solution is an important limiting factor in the TPS adsorption process and, consequently, it is necessary to optimize the $\mathrm{pH}$ of the solution to obtain effective interactions between TPS and MPS. Previous studies confirmed that $\mathrm{pH}$ value had great influence on the interaction between different polyphenols and macromolecule materials $[24,25]$. In this context, a higher adsorption capacity of TPS onto MPS was obtained by optimizing the $\mathrm{pH}$ of the adsorption solution. As shown in Figure 1A, the $\mathrm{Q}_{\mathrm{e}}$ of TPS increased with $\mathrm{pH}$ up to 6.7 and then began to decrease. The maximum adsorption of TPS onto MPS was obtained at $\mathrm{pH}$ 6.7; thus, this $\mathrm{pH}$ value was used for the following research.
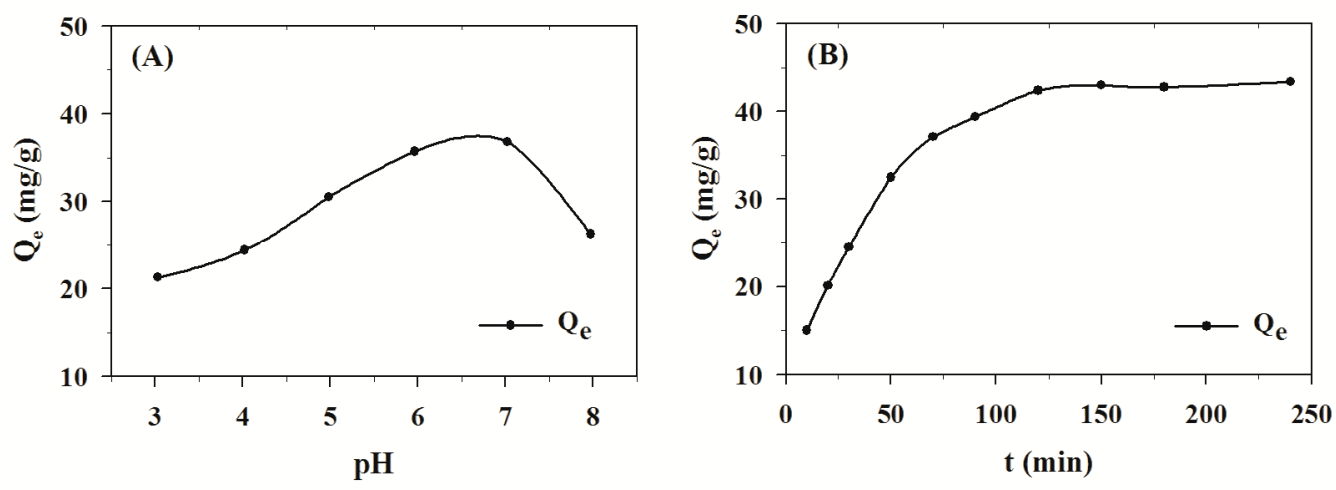

Figure 1. Effect of $\mathrm{pH}(\mathbf{A})$ and time (B) on the adsorption of tea polyphenols (TPS) by microporous starch (MPS) (MPS dose $=1.0 \mathrm{~g} / 50 \mathrm{~mL}$, Temp. = $293 \mathrm{~K}$ ).

\subsection{Effect of Contact Time}

The static adsorption curve was studied to obtain the most suitable adsorption time. The result is presented in Figure $1 \mathrm{~B}$ (Initial conc. $=1.2 \mathrm{mg} / \mathrm{mL}, \mathrm{pH}=6.7$ ). The adsorption capacity quickly increased to $39.4 \mathrm{mg} / \mathrm{g}$ within $90 \mathrm{~min}$ at $293 \mathrm{~K}$. With the increase in contact time, adsorption equilibrium was achieved at approximately $120 \mathrm{~min}$ and reached a plateau at an adsorption capacity of $42.4 \mathrm{mg} / \mathrm{g}$. Therefore, the most appropriate adsorption time was $120 \mathrm{~min}$. The result obtained from this experiment was further used to fit the adsorption kinetic models.

\subsection{Adsorption Kinetics}

Adsorption kinetics describe the adsorption rate of the adsorbate on an adsorbent at a specific initial concentration and temperature, and the time required for the adsorption from the beginning of 
the reaction to equilibrium is determined from the kinetics [26]. For a solid-liquid adsorption process, the solute transfer is usually characterized by either external mass transfer or intra-particle diffusion or both [27]. Various kinetics models have been proposed for adsorption, such as the pseudo first-order, the pseudo second-order and Weber and Morris intra-particle diffusion kinetics models, etc.

\subsubsection{Pseudo First-Order Model}

The Lagergren rate equation is one of the most widely used adsorption rate equations to describe adsorption processes. The pseudo first-order equation can be expressed in the following form, given as Equation (1) [28]:

$$
\frac{\mathrm{d} \mathrm{Q}_{\mathrm{t}}}{\mathrm{dt}}=\mathrm{k}_{\mathrm{f}}\left(\mathrm{Q}_{\mathrm{e}}-\mathrm{Q}_{\mathrm{t}}\right)
$$

Equation (1) can be integrated as follows:

$$
\log \left(Q_{e}-Q_{t}\right)=\log Q_{e}-\frac{k_{f}}{2.303} t
$$

where $t$ is the contact time $(\mathrm{min})$, and $\mathrm{Q}_{\mathrm{t}}(\mathrm{mg} / \mathrm{g})$ and $\mathrm{Q}_{\mathrm{e}}(\mathrm{mg} / \mathrm{g})$ are the quantities of TPS absorbed at time $t$ and at equilibrium, respectively. $k_{f}$ is the rate constant of the pseudo first-order model (1/min).

Plotting $\log \left(Q_{e}-Q_{t}\right)$ versus $t$ allows the calculation of the rate constant $k_{f}$ and $Q_{e}$. The result is shown in Figure 2A. The linear plot displays the effectiveness of this model [28]. The linear correlation coefficients $\left(\mathrm{R}^{2}\right)$ of the initial concentration of $0.3 \mathrm{mg} / \mathrm{mL}, 0.6 \mathrm{mg} / \mathrm{mL}$ and $1.2 \mathrm{mg} / \mathrm{mL}$ were 0.96015 , 0.98879 and 0.97810 , respectively. Kinetics parameter $\mathrm{k}_{\mathrm{f}}$ suggested that the adsorption rate was very fast at the beginning of the adsorption process for TPS onto MPS.
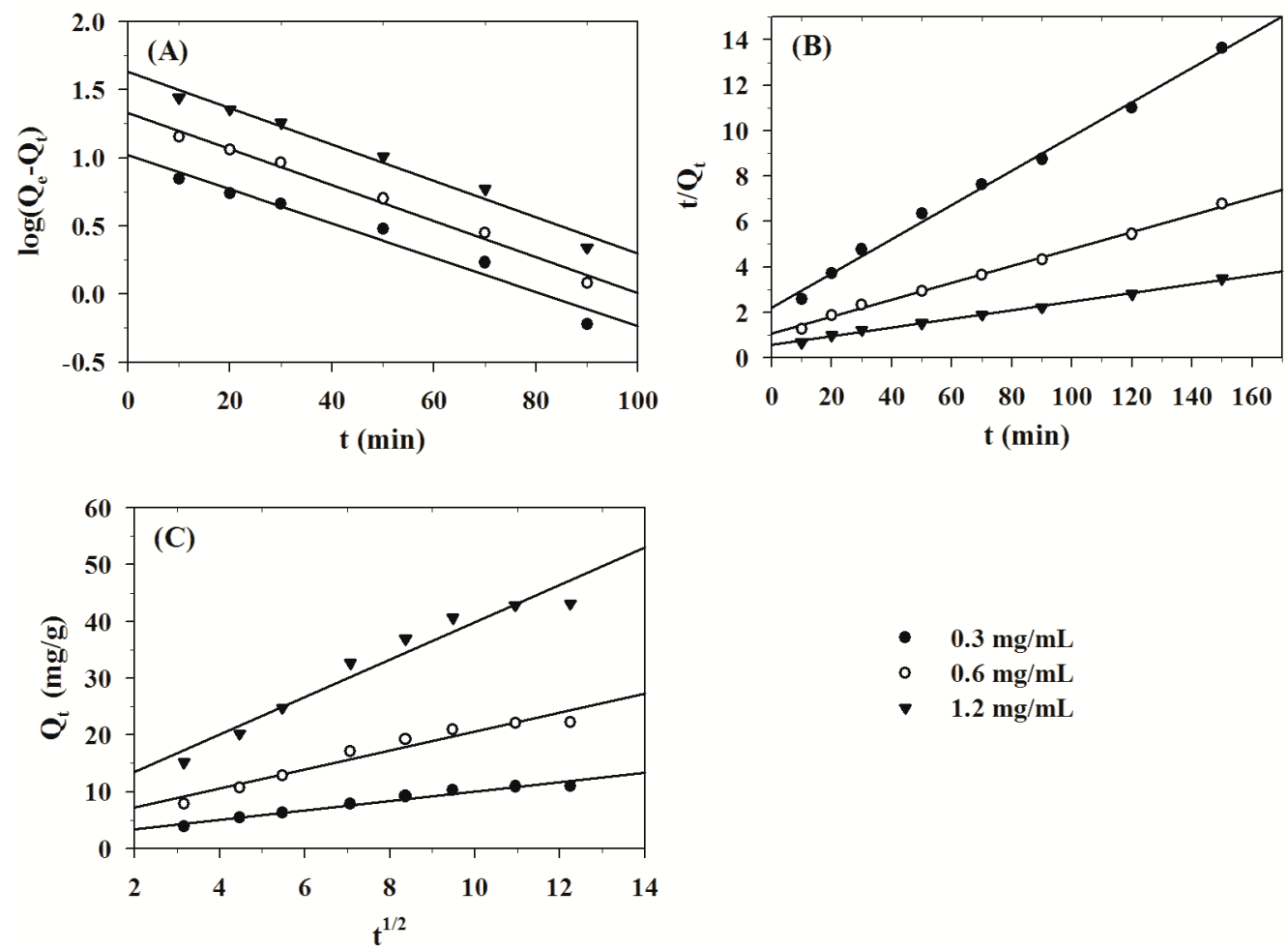

- $0.3 \mathrm{mg} / \mathrm{mL}$

- $0.6 \mathrm{mg} / \mathrm{mL}$

> $\quad 1.2 \mathrm{mg} / \mathrm{mL}$

Figure 2. Pseudo first-order kinetic plot (A), pseudo second-order kinetic plot (B) and Weber and Morris intra-particle diffusion kinetic model (C) for the adsorption of TPS onto MPS (MPS dose $=1.0 \mathrm{~g} / 50 \mathrm{~mL}$, $\mathrm{pH}=6.7$, Initial conc. $=0.3-1.2 \mathrm{mg} / \mathrm{mL}$, Temp. $=293 \mathrm{~K})$. 


\subsubsection{Pseudo Second-Order Model}

The pseudo second-order equation assumed that the adsorption rate was proportional to the number of active sites occupied onto the adsorbent [29]. The pseudo-second-order model is given by Equation (3) [30]:

$$
\frac{\mathrm{dQ}_{\mathrm{t}}}{\mathrm{dt}}=\mathrm{k}_{\mathrm{s}}\left(\mathrm{Q}_{\mathrm{e}}-\mathrm{Q}_{\mathrm{t}}\right)^{2}
$$

Equation (3) can be rearranged as follows:

$$
\frac{\mathrm{t}}{\mathrm{Q}_{\mathrm{t}}}=\frac{1}{\mathrm{k}_{\mathrm{s}} \mathrm{Q}_{\mathrm{e}}^{2}}+\frac{1}{\mathrm{Q}_{\mathrm{e}}} \mathrm{t}
$$

where $t$ is the contact time $(\mathrm{min})$, and $\mathrm{Q}_{\mathrm{t}}(\mathrm{mg} / \mathrm{g})$ and $\mathrm{Q}_{\mathrm{e}}(\mathrm{mg} / \mathrm{g})$ are the quantities of TPS absorbed at time $t$ and at equilibrium, respectively. $k_{\mathrm{s}}$ is the rate constant of the pseudo second-order model (g/mg min).

$\mathrm{Q}_{\mathrm{e}}$ and $\mathrm{k}_{\mathrm{s}}$ can be calculated from a plot of $t / \mathrm{Q}_{t}$ versus $t$. The result is shown in Figure $2 \mathrm{~B}$. The linear correlation coefficients $\left(\mathrm{R}^{2}\right)$ of the initial concentration of $0.3 \mathrm{mg} / \mathrm{mL}, 0.6 \mathrm{mg} / \mathrm{mL}$ and $1.2 \mathrm{mg} / \mathrm{mL}$ were $0.99471,0.99640$ and 0.99586 , respectively. The straight linearity suggested that the pseudo second-order model was fit for describing the adsorption kinetics of TPS onto MPS. The correlation coefficient of the pseudo second-order model was higher than the pseudo first-order model, which may imply that the pseudo second-order is more suitable to describe the kinetics.

\subsubsection{Weber and Morris Intra-Particle Diffusion Model}

Adsorption kinetics were controlled by the adsorption mechanism and rate-limiting step of the process [31]. The adsorption rate can be limited by film diffusion and/or intra-particle diffusion [32]. The intra-particle diffusion model can be expressed as follow:

$$
\mathrm{Q}_{\mathrm{t}}=\mathrm{k}_{\mathrm{id}} \mathrm{t}^{1 / 2}+\mathrm{C}
$$

where $Q_{t}(\mathrm{mg} / \mathrm{g})$ is the quantities of TPS absorbed at time $t$, and $k_{i d}$ is the intra-particle diffusion rate constant. The values of the intercept, $\mathrm{C}$, provide an indication of the thickness of the boundary layer between the adsorbent and adsorbate. The larger the value of $C$, the greater the boundary layer effect is.

The linear correlation coefficients $\left(\mathrm{R}^{2}\right)$ of the initial concentration of $0.3 \mathrm{mg} / \mathrm{mL}, 0.6 \mathrm{mg} / \mathrm{mL}$ and $1.2 \mathrm{mg} / \mathrm{mL}$ were $0.96317,0.94311$ and 0.94871 , respectively. The result is presented in Figure 2C. If the plot shows a straight line that passes through the origin, the adsorption process is conducted only by intra-particle diffusion. If the plot does not pass through the origin, the adsorption process is conducted by two or more diffusion mechanisms $[33,34]$. The result showed that the straight lines did not pass through the origin, suggesting that both film diffusion and intra-particle diffusion were significant between MPS and TPS.

\subsection{Adsorption Isotherm}

Adsorption isotherms describe the adsorbate distribution between that adsorbed onto the adsorbent and that in solution when adsorption equilibrium is achieved at a steady temperature $[35,36]$. At present, the most common models are the Langmuir, Freundlich and Tempkin isotherms. Consequently, the Langmuir, Freundlich and Temkin isotherm models were employed to describe the equilibrium characteristics of adsorption of TPS onto MPS. 


\subsubsection{Langmuir Isotherm}

The Langmuir isotherm is given for homogenous adsorption where the adsorption process has equal activation energy. The Langmuir isotherm can be represented as follows [37]:

$$
\frac{C_{e}}{Q_{e}}=\frac{1}{K_{L} Q_{m}}+\frac{C_{e}}{Q_{m}}
$$

where $Q_{e}$ is the equilibrium quantity of absorbed TPS $(\mathrm{mg} / \mathrm{g}), \mathrm{C}_{\mathrm{e}}$ is the equilibrium concentration $(\mathrm{mg} / \mathrm{mL}), \mathrm{Q}_{\mathrm{m}}$ is the calculated maximum quantities of absorbed TPS, and $\mathrm{K}_{\mathrm{L}}$ is the Langmuir constant. A plot of $C_{e} / Q_{e}$ versus $C_{e}$ is a straight line with intercept $1 / Q_{m} K_{L}$ and slope $1 / Q_{m}$. The maximum adsorption capacity of TPS onto MPS at the temperature of $293 \mathrm{~K}$ was approximately $63.1 \mathrm{mg} / \mathrm{g}$. Langmuir plot for the adsorption of TPS onto MPS is presented in Figure 3A.
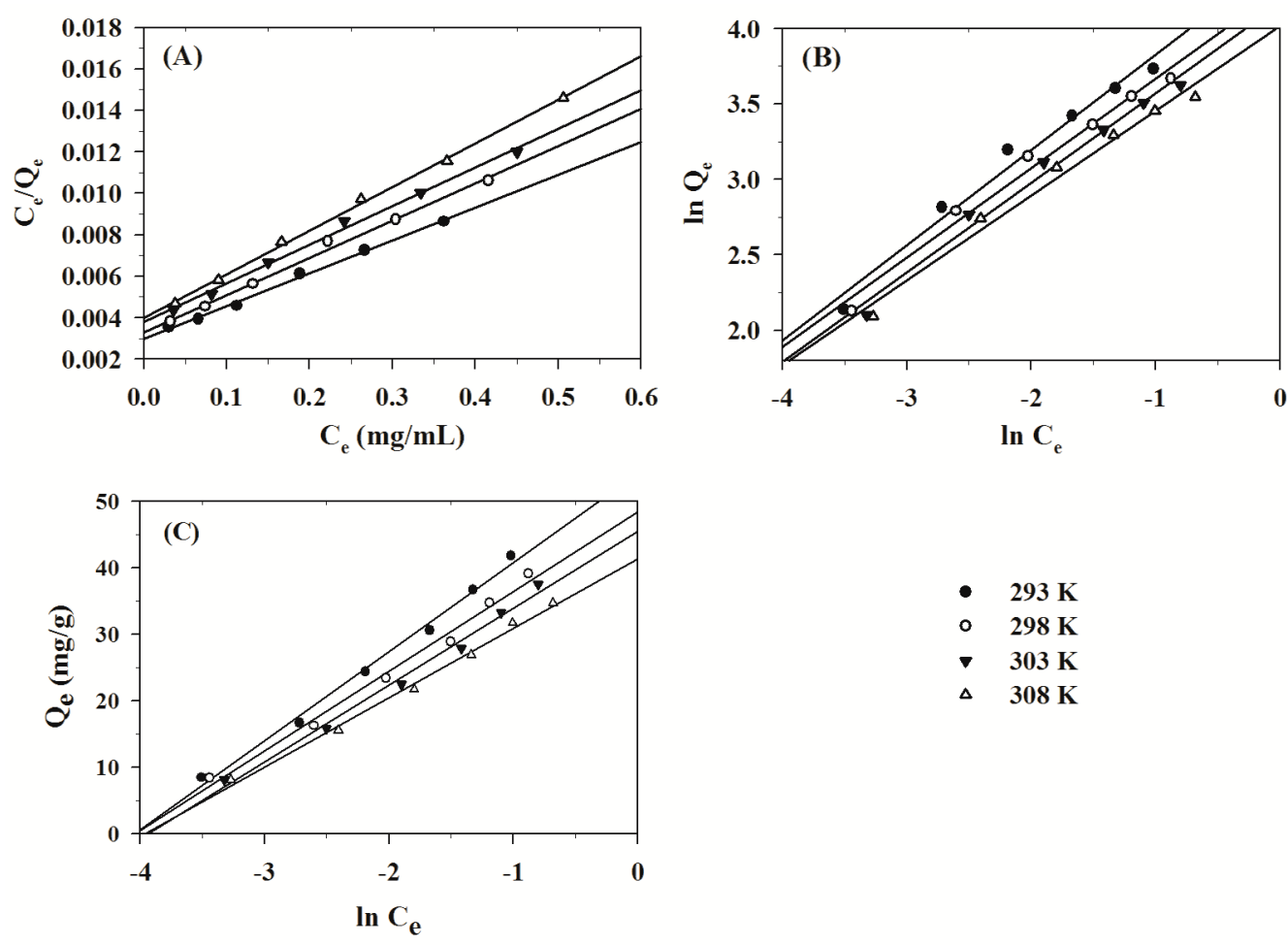

- $293 \mathrm{~K}$

- $298 \mathrm{~K}$

$\rightarrow \quad 303 \mathrm{~K}$

$\triangle \quad 308 \mathrm{~K}$

Figure 3. Langmuir adsorption isotherm (A), Freundlich adsorption isotherm (B) and Tempkin adsorption isotherm (C) for the adsorption of TPS onto MPS (MPS dose $=1.0 \mathrm{~g} / 50 \mathrm{~mL}, \mathrm{pH}=6.7$, Adsorption time $=120 \mathrm{~min}$, Initial conc. $=0.2-1.2 \mathrm{mg} / \mathrm{mL}$, Temp. $=293-308 \mathrm{~K}$ ).

The linear correlation coefficients $\left(R^{2}\right)$ of the temperature of $293 \mathrm{~K}, 298 \mathrm{~K}, 303 \mathrm{~K}$ and $308 \mathrm{~K}$ were $0.99600,0.99435,0.99519$ and 0.99820 , respectively. The correlation coefficient $\left(R^{2} \geq 0.99435\right)$ of the Langmuir equation was high, which implied that the Langmuir isotherm model was favorable. In addition, the essential characteristics of the Langmuir isotherm can be made on the basis of a dimensionless constant equilibrium, that is separation factor $R_{L}$ [38,39], which is defined by:

$$
\mathrm{R}_{\mathrm{L}}=\frac{1}{1+\mathrm{K}_{\mathrm{L}} \mathrm{C}_{0}}
$$

where $\mathrm{K}_{\mathrm{L}}(\mathrm{L} / \mathrm{mg})$ and $\mathrm{C}_{0}(\mathrm{mg} / \mathrm{mL})$ are the Langmuir constant and the initial concentration of TPS, respectively. The value of $R_{L}$ suggest whether the isotherm is unfavorable $\left(R_{L}>1\right)$, linear $\left(R_{L}=1\right)$, favorable $\left(0<R_{L}<1\right)$, or irreversible $\left(R_{L}=0\right)$ [39]. The values of $R_{L}$ at $293 \mathrm{~K}, 298 \mathrm{~K}, 303 \mathrm{~K}$ and $308 \mathrm{~K}$ were $0.09579-0.01735,0.07776-0.01386,0.06605-0.01165$ and $0.05612-0.00981$, respectively. The values of $\mathrm{R}_{\mathrm{L}}$ also implied that the Langmuir isotherm was favorable. 


\subsubsection{Freundlich Isotherm}

The Freundlich isotherm model characterizes the adsorption process based on heterogeneous surfaces [31]. The Freundlich isotherm can be represented as follows:

$$
\ln \mathrm{Q}_{\mathrm{e}}=\ln \mathrm{K}_{\mathrm{F}}+\frac{1}{\mathrm{n}} \ln \mathrm{C}_{\mathrm{e}}
$$

where $Q_{e}$ is the equilibrium quantity of absorbed TPS $(\mathrm{mg} / \mathrm{g}), \mathrm{C}_{\mathrm{e}}$ is the equilibrium concentration $(\mathrm{mg} / \mathrm{mL})$, and $\mathrm{K}_{\mathrm{F}}$ and $1 / \mathrm{n}$ are the Freundlich constants.

The linear plot of $\ln Q_{e}$ versus $\ln C_{e}$ is shown in Figure 3B. The linear correlation coefficients $\left(R^{2}\right)$ of the temperature of $293 \mathrm{~K}, 298 \mathrm{~K}, 303 \mathrm{~K}$ and $308 \mathrm{~K}$ were $0.97858,0.98307,0.98418$ and 0.98190 , respectively. The high correlation coefficient $\left(R^{2} \geq 0.97858\right)$ suggested that the Freundlich adsorption isotherm was suitable. The values of $1 / \mathrm{n}$ at $293 \mathrm{~K}, 298 \mathrm{~K}, 303 \mathrm{~K}$ and $308 \mathrm{~K}$ were $0.63022,0.59253$, 0.59263 and 0.56199 , respectively. The value of $1 / \mathrm{n}$ suggests the type of isotherm. When $1>1 / n>0$, the adsorption isotherm is favorable; when $1 / \mathrm{n}=1$, the adsorption isotherm is irreversible; and when $1 / n>1$, the adsorption isotherm is unfavorable $[34,35]$. Consequently, the value of $1 / n$ also implied that the adsorption of TPS onto MPS was favorable.

\subsubsection{Tempkin Isotherm}

The assumption behind the Tempkin isotherm is that the heat of adsorption of all molecules in the layer decrease with coverage due to adsorbate-adsorbate interaction. The Tempkin isotherm is given by Equation (9) [33,34]:

$$
\mathrm{Q}_{\mathrm{e}}=\frac{\mathrm{RT}}{\mathrm{b}} \ln \left(\mathrm{K}_{\mathrm{T}} \mathrm{C}_{\mathrm{e}}\right)
$$

Equation (9) can be integrated as follows:

$$
\mathrm{Q}_{\mathrm{e}}=\mathrm{B}_{1} \ln \mathrm{K}_{\mathrm{T}}+\mathrm{B}_{1} \ln \mathrm{C}_{\mathrm{e}}
$$

where $B_{1}=R T / b, K_{T}$ is the Tempkin isotherm energy constant $(L / m g)$ that corresponds to the maximum binding energy and constant $B_{1}$ is related to the heat of adsorption. Regression of $Q_{e}$ against $\ln C_{e}$ enables the calculation of the isotherm constants $K_{T}$ and $B_{1}$. The plot of $Q_{e}$ versus $\ln C_{e}$ is shown in Figure 3C. The linear correlation coefficients $\left(R^{2}\right)$ of the temperature of $293 \mathrm{~K}, 298 \mathrm{~K}, 303 \mathrm{~K}$ and $308 \mathrm{~K}$ were $0.99198,0.98919,0.98991$ and 0.99359 , respectively. The high correlation coefficient $\left(R^{2} \geq 0.98919\right)$ indicated that the Tempkin adsorption isotherm was suitable.

All adsorption isotherms of the Langmuir, Freundlich and Tempkin are shown in Figure 3. From the figure it is clear that all the evaluated equilibrium isotherm models produced good fits for the experimental data. Compared to the Langmuir isotherm model, the average correlation coefficient of the Freundlich and Tempkin isotherm models were lower, and consequently the Langmuir isotherm model may be more suitable for the process of adsorption in this study. Based on the results of the study, the best isotherm models fitted for the adsorption of TPS onto MPS were determined in the following order: Langmuir $>$ Tempkin $>$ Freundlich.

\subsection{Thermodynamic Study of Adsorption}

Thermodynamic parameters can describe the thermodynamic behavior associated with TPS adsorption onto MPS from an aqueous solution. Therefore, the change in free energy $\left(\Delta G^{0}\right)$, enthalpy $\left(\Delta \mathrm{H}^{0}\right)$ and entropy $\left(\Delta \mathrm{S}^{0}\right)$ were determined using the following equations [40]:

$$
\begin{gathered}
\mathrm{K}_{\mathrm{c}}=\frac{\mathrm{Q}_{\mathrm{e}}}{\mathrm{C}_{\mathrm{e}}} \\
\ln \mathrm{K}_{\mathrm{c}}=\frac{\Delta \mathrm{H}^{0}}{\mathrm{RT}}+\frac{\Delta \mathrm{S}^{0}}{\mathrm{R}}
\end{gathered}
$$




$$
\Delta \mathrm{G}^{0}=\Delta \mathrm{H}^{0}-\mathrm{T} \Delta \mathrm{S}^{0}
$$

where $K_{c}$ is the distribution coefficient $(\mathrm{mL} / \mathrm{g}) ; Q_{e}$ and $C_{e}$ are the equilibrium quantities of absorbed TPS ( $\mathrm{mg} / \mathrm{g}$ ) and the equilibrium concentration $(\mathrm{mg} / \mathrm{mL})$, respectively; and $\mathrm{T}$ is the absolute temperature in Kelvin; and $\mathrm{R}$ is the ideal gas constant $(8.314 \mathrm{~J} / \mathrm{mol} \mathrm{K})$. The parameters of $\Delta \mathrm{H}^{0}$ and $\Delta \mathrm{S}^{0}$ can be calculated from the slope and intercept of the plot of $\ln \mathrm{K}_{\mathrm{c}}$ versus $1 / \mathrm{T}$ (Figure 4). The thermodynamic parameters calculated for the adsorption of TPS onto MPS are summarized in Table 1.

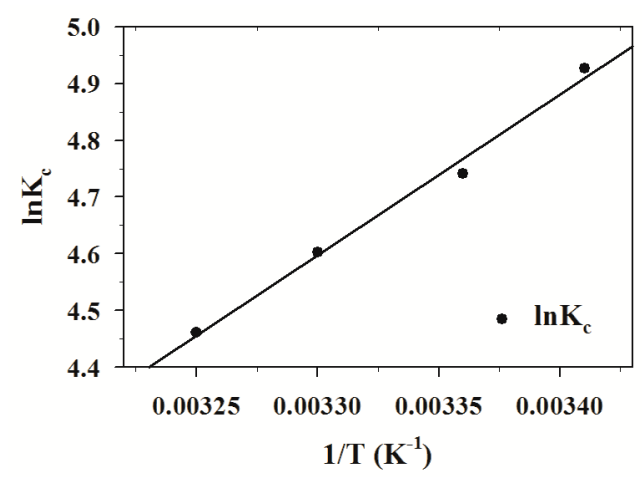

Figure 4. Plots of $\ln \mathrm{K}_{\mathrm{c}}$ versus $1 / \mathrm{T}$ for the adsorption of TPS onto MPS (MPS dose $=1.0 \mathrm{~g} / 50 \mathrm{~mL}$, $\mathrm{pH}=6.7$, Adsorption time $=120 \mathrm{~min}$, Initial conc. $=1.0 \mathrm{mg} / \mathrm{mL}$, Temp. $=293-308 \mathrm{~K}$ ).

Table 1. Thermodynamic parameters for the adsorption of TPS onto MPS.

\begin{tabular}{cccc}
\hline $\mathbf{T}(\mathrm{K})$ & $\Delta \mathbf{G}^{\mathbf{0}}(\mathbf{k J} / \mathbf{m o l ~ K})$ & $\Delta \mathbf{H}^{\mathbf{0}}(\mathbf{k J} / \mathbf{m o l})$ & $\Delta \mathbf{S}^{\mathbf{0}}(\mathrm{J} / \mathbf{m o l ~ K})$ \\
\hline 293 & -11.9748 & & \\
298 & -11.7858 & -23.0526 & -37.8082 \\
303 & -11.5967 & & \\
308 & -11.4077 & & \\
\hline
\end{tabular}

The values of $\Delta \mathrm{G}^{0}$ tended to be negative as temperature decreases, suggesting that the adsorption process is more suitable at a lower temperature. The negative value of $\Delta \mathrm{H}^{0}$ and $\Delta \mathrm{G}^{0}$ confirmed the exothermic and spontaneous nature of the adsorption process [40]. In addition, the values of $\Delta \mathrm{G}^{0}$ are in the range of -20 to $0 \mathrm{~kJ} / \mathrm{mol} \mathrm{K}$, indicating that the adsorption of TPS onto MPS is typically via physical adsorption [41]. It was reported that the energy of adsorption from hydrogen bond forces was in the range of 2 to $40 \mathrm{~kJ} / \mathrm{mol}$ [42]. The value (-23.0526 kJ/mol) of $\Delta \mathrm{H}^{0}$ suggested that hydrogen bonding interaction between TPS and MPS played an important role in the adsorption process. The negative value of $\Delta S^{0}$ implied that the randomness decreased at the solid-solution interface during the adsorption of TPS onto MPS.

\subsection{The Stability of Microporous Starch (MPS)-Loaded Tea Polyphenols (TPS)}

The samples were stored at ambient temperature, under dry conditions. The stabilities of free TPS and MPS-loaded TPS are shown in Figure 5. From 1 to 15 days, the TPS retention rate value of free TPS changed less. Following an increase in storage time from 15 to 90 days, the retention rate values of free TPS decreased rapidly. The whole reducing ratio from 1 to 90 days relative to the initial quantity was approximately $18.2 \%$, whereas that of MPS-loaded TPS was minor, which was $8.7 \%$. The change in retention rate value of TPS showed that the retention rate of TPS for MPS-loaded TPS was significantly different. Therefore, MPS-loaded TPS had better stability and could be stored for a long time. 


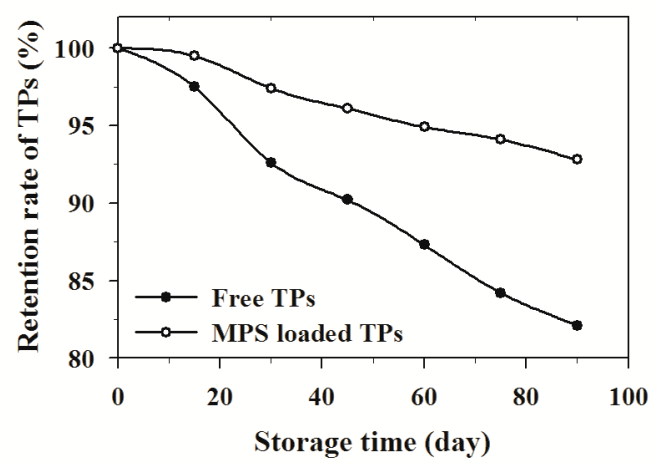

Figure 5. Storage stability of TPS adsorbed onto MPS at ambient temperature.

\subsection{Characterization of the Adsorbents}

It is well-known that the surface morphology of the adsorbent can affect its adsorption performance [43-45]. Figure 6 shows scanning electron microscope (SEM) images obtained for MPS before and after the adsorption of TPS. From the SEM images, the microporous starch granules have polygonal, granular shapes with relatively smooth surfaces. MPS-loaded TPS did not change the surface morphology of the granular starch. However, the pore diameter of starch decreased or nearly disappeared after adsorption, suggesting that TPS molecules diffused toward the pores of MPS and, therefore, were adsorbed. The adsorption performance of MPS mainly depends on microporous characteristics. Therefore, the adsorption capacity of MPS is proportional to specific surface area. Being protected by the crust of the microporous starch, the adsorbed TPS cannot easily oxidize and the microporous starch shows good protection performance.

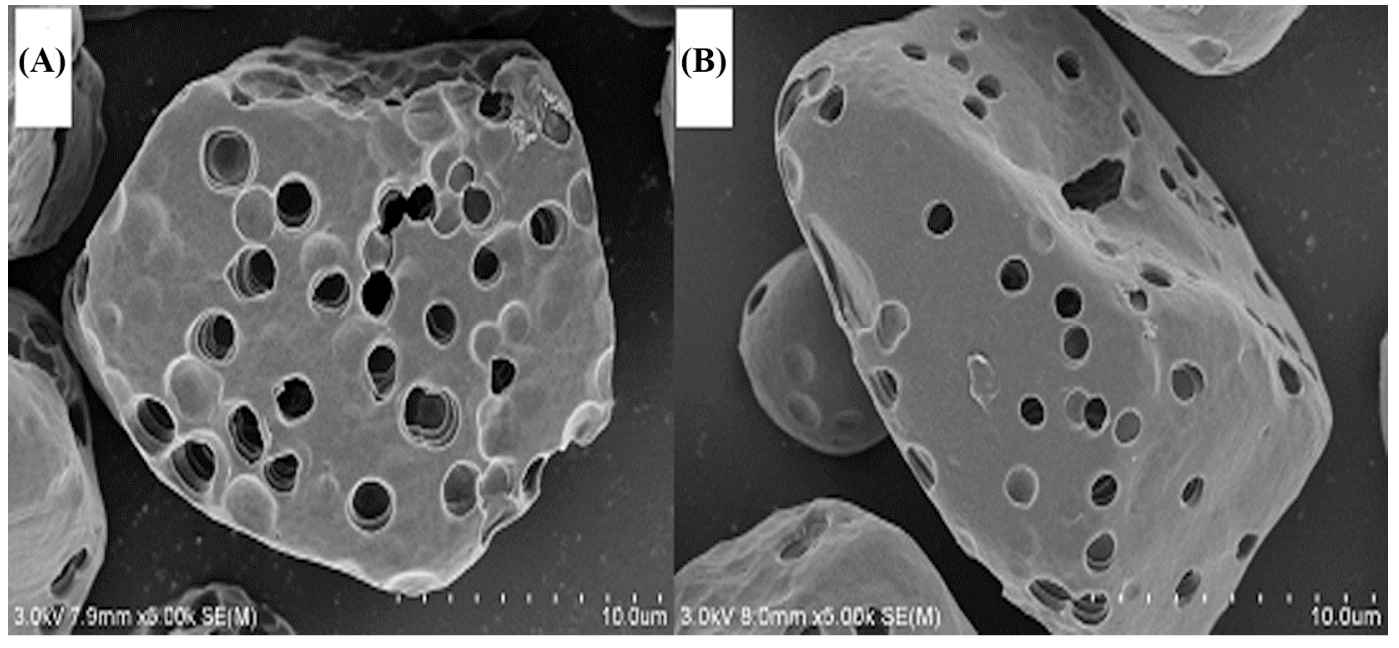

Figure 6. Scanning electron microscope (SEM) images of MPS before (A) and after (B) adsorption of TPS, magnified 5000 times.

The Fourier transform infrared (FT-IR) spectra of MPS before and after the adsorption of the TPS also indicated these interactions (Figure 7). The characteristic absorption peaks of MPS have no obvious change before and after the adsorption of TPS, which is attributed to the fact that the adsorption process does not result in a change in the molecular structure of the starch [46]. Therefore, the infrared (IR) analysis shows that there are no new chemical bonds formed between TPS and MPS. The results suggested that TPS was adsorbed on MPS mainly through the formation of hydrogen bond complexes with functional groups on the microporous starch surface, which is consistent with the results obtained above. 


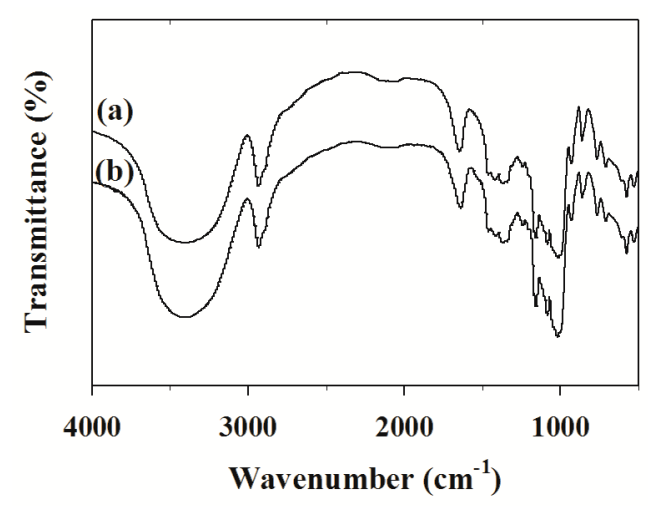

Figure 7. Fourier transform infrared (FT-IR) spectra of MPS before (a) and after (b) adsorption of TPS.

\section{Materials and Methods}

\subsection{Materials}

Corn starch (food-grade) was obtained from Shandong Linghua Group Co., Ltd., (Jining, China). $\alpha$-amylase (activity $\geq 3.7 \mathrm{U} / \mathrm{mg}$ ) and glucoamylase (activity $\geq 100 \mathrm{U} / \mathrm{mg}$ ) were purchased from Beijing Aoboxing Biotechnology Co., Ltd., (Beijing, China). Tea polyphenols (TPS, concentration $\geq 98 \%$ ) were purchased from Shanghai Winherb Medical Technology Co., Ltd., (Shanghai, China), and were used without further purification. Folin-Ciocalteu reagent was purchased from Sigma-Aldrich Co., Ltd., (Shanghai, China). Disodium hydrogen phosphate, citric acid and ethanol were analytical reagent grade and applied as received. All reagents were prepared using distilled water.

\subsection{Preparation of Microporous Starch}

Microporous starch (MPS) was prepared by hydrolyzing the native corn starch with $\alpha$-amylase and glucoamylase [43]. Approximately $25 \mathrm{~g}$ native corn starch and $0.5 \mathrm{~g}$ admixture of $\alpha$-amylase and glucoamylase $(6: 1, w / w)$ were suspended in $200 \mathrm{~mL}$ phosphate buffer saline (PBS) at pH $5.5(0.2 \mathrm{M}$ disodium hydrogen phosphate, $0.1 \mathrm{M}$ citric acid) and stirred at $50^{\circ} \mathrm{C}$ for $12 \mathrm{~h}$. Then, the mixture was adjusted to $\mathrm{pH} 10$ with $1 \mathrm{~mol} / \mathrm{L} \mathrm{NaOH}$ and was filtered through the suction filter and washed with distilled water four times; the product was dried via vacuum freeze drying and was finally ground and sifted with a vibrating screen (100 meshes) for separation.

\subsection{Determination of Tea Polyphenols Content}

The amount of tea polyphenols was determined by Folin-Ciocalteu's colorimetric method with slight modification [47,48]. Tea polyphenol aqueous solutions with concentrations ranging from 10 to $60 \mu \mathrm{g} / \mathrm{mL}$ were employed to establish the calibration curve $\left(\mathrm{y}=0.0108 \mathrm{x}+0.037 ; \mathrm{R}^{2}=0.9972\right)$. In this method, $1.0 \mathrm{~mL}$ of sample was diluted with distilled water to obtain absorbance in the scope of the obtained calibration curve. Thereafter, $5.0 \mathrm{~mL} \mathrm{10 \%} \mathrm{Folin-Ciocalteu} \mathrm{reagent} \mathrm{was} \mathrm{added} \mathrm{and} \mathrm{allowed} \mathrm{to}$ stand for $5 \mathrm{~min}$ for the reaction. The mixture was regulated by $4.0 \mathrm{~mL} \mathrm{7.5 \%} \mathrm{sodium} \mathrm{carbonate} \mathrm{and}$ was kept in dark place at room temperature $(60 \mathrm{~min})$. The absorbance of the resulting blue color was determined at $765 \mathrm{~nm}$ using an ultraviolet-visible (UV/VIS) spectrometer (Lambda 35 PerkinElmer, Waltham, MA, USA) (28). The quantitative calculation was carried out according to the calibration curve of TPS.

\subsection{Batch Adsorption Experiments}

Approximately $1.0 \mathrm{~g}$ MPS was added to $50 \mathrm{~mL}$ aqueous TPS solution in a series of $100 \mathrm{~mL}$ glass-stopper Erlenmeyer flasks. The mixture was stirred on a magnetic stirring apparatus at a constant speed of $120 \mathrm{rpm}$ in a thermostat water bath. After a certain adsorption time, the mixture 
was centrifuged for $10 \mathrm{~min}$ at $8,000 \mathrm{rpm}$. The concentration of TPS in the supernatant solution was measured using a UV/VIS spectrometer (Lambda 35 PerkinElmer, Waltham, MA, USA) at $765 \mathrm{~nm}$.

The adsorption capacity was calculated according to Equation (14):

$$
\mathrm{Q}=\frac{\left(\mathrm{C}_{\mathrm{i}}-\mathrm{C}_{\mathrm{t}}\right) \mathrm{V}}{\mathrm{W}}
$$

where $Q$ is the adsorption capacity of MPS $(\mathrm{mg} / \mathrm{g})$, and $C_{\mathrm{i}}$ and $C_{\mathrm{t}}(\mathrm{mg} / \mathrm{L})$ are the initial and terminal concentrations of TPS in the adsorption solution, respectively. $V(\mathrm{~mL})$ is the volume of the adsorption solution and $W(\mathrm{mg})$ is the mass of the adsorbent.

The $\mathrm{pH}$ effect was employed by the method of batching adsorption as mentioned above. The initial concentration of TPS was $1.0 \mathrm{mg} / \mathrm{mL}$. The $\mathrm{pH}$ was adjusted from 3 to 8 by regulation of $0.1 \mathrm{~mol} / \mathrm{L}$ $\mathrm{HCl}$ or $\mathrm{NaOH}$. After it was stirred for $150 \mathrm{~min}$, the mixture was subsequently centrifuged for $10 \mathrm{~min}$ at $8,000 \mathrm{rpm}$ for the separation of solid phases from the aqueous phase. The concentration of TPS was determined according to 3.3. All experiments were repeated three times.

\subsection{The Stability Evaluation of MPS-Loaded TPS}

The samples were stored at ambient temperature, in dry conditions and were assayed for the retention of TPS every 15 days to study the storage stability of TPS. The desorption of MPS-loaded TPS was performed by adding $50 \mathrm{~mL}$ of an aqueous ethanol mixture $(70 \%, v / v)$ [49]. The solution was again stirred under the same conditions as in the absorption. Experiments were performed with free TPS as blank controls. The retention rates of the TPS are calculated according to Equation (15):

$$
R(\%)=\frac{C_{a}}{C_{b}} \times 100 \%
$$

where $C_{b}$ and $C_{a}$ are the content of TPS in the sample before treatments and after the treatments, respectively.

\subsection{Characterization Methods}

The morphologies of MPS and MPS-loaded TPS were investigated using a scanning electron microscope (SEM, S-3800N, Hitachi Limited, Tokyo, Japan). FT-IR analyses of MPS and MPS-loaded TPS were performed using Fourier transform infrared spectroscopy (Nicolette is50, Thermo Fisher Scientific, Waltham, MA, USA). The samples were prepared by making pellets with dried IR-grade $\mathrm{KBr}$ and 64 scans were signal-averaged to reduce spectral noise.

\section{Conclusions}

Microporous starch (MPS) granules were prepared via the partial hydrolysis of starch using $\alpha$-amylase and glucoamylase. The results of scanning electron microscopy (SEM) analysis revealed the microporous structure of the MPS. As an adsorbent of tea polyphenols (TPS), MPS shows a much higher adsorption capacity under the right conditions. The adsorption kinetics of TPS onto MPS conforms to the pseudo second-order model. The equilibrium adsorption data were well-fitted by the Langmuir isotherm model. The $\Delta \mathrm{G}^{0}$ values of the adsorption process become less negative as temperature increased from $293 \mathrm{~K}$ to $308 \mathrm{~K}$, and all values of $\Delta \mathrm{H}^{0}$ are negative, which implies that the adsorption process is exothermic and spontaneous. The FT-IR analysis shows that there are no new chemical bonds formed between TPS and MPS, and the small values of $\Delta \mathrm{G}^{0}$ between -20 and $0 \mathrm{~kJ} / \mathrm{mol}$ reveal that the adsorption mechanism of TPS onto MPS is typical physical adsorption. In addition, MPS-loaded TPS had better stability during long-term storage at ambient temperature. 
Author Contributions: X.D. designed the experiments and revised the manuscript. X.H. carried out all the experiments, analyzed the data and wrote the manuscript. All the authors read and approved the final manuscript.

Funding: This study was financial supported by a grant from the National Natural Science Foundation of China (No. 31471700).

Conflicts of Interest: The authors declare no conflict of interest.

\section{References}

1. Vuong, Q.V.; Golding, J.B.; Nguyen, M.; Roach, P.D. Extraction and isolation of catechins from tea. J. Sep. Sci. 2010, 33, 3415-3428. [CrossRef] [PubMed]

2. Hashimoto, F.; Ono, M.; Masuoka, C.; Ito, Y.; Sakata, Y.; Shimizu, K.; Nishioka, I.; Nohara, T. Evaluation of the anti-oxidative effect (in vitro) of tea polyphenols. Biosci. Biotech. Bioch. 2003, 67, 396-401. [CrossRef]

3. Balasundram, N.; Sundram, K.; Samman, S. Phenolic compounds in plants and agri-industrial by-products: Antioxidant activity, occurrence, and potential uses. Food Chem. 2006, 99, 191-203. [CrossRef]

4. Ide, K.; Matsuoka, N.; Yamada, H.; Furushima, D.; Kawakami, K. Effects of tea catechins on Alzheimer's disease: Recent updates and perspectives. Molecules 2018, 23, 2357. [CrossRef]

5. Shirakami, Y.; Shimizu, M. Possible mechanisms of green tea and its constituents against cancer. Molecules 2018, 23, 2284. [CrossRef]

6. Gramza, A.; Korczak, J.; Amarowicz, R. Tea polyphenols-their antioxidant properties and biological activity-a review. Pol. J. Food Nutr. Sci. 2005, 14, 219-235.

7. Mukhtar, H.; Ahmad, N. Tea polyphenols: Prevention of cancer and optimizing health. Am. J. Clin. Nutr. 2000, 71, 1698-1702. [CrossRef]

8. Yan, H.; Zhengbiao, G.U. Morphology of modified starches prepared by different methods. Food Res. Int. 2010, 43, 767-772. [CrossRef]

9. Wang, X.Y.; Wang, H.Q.; Dai, Q.F.; Li, Q.Y.; Yang, J.H.; Zhang, A.N.; Yan, Z.X. Preparation of novel porous carbon spheres from corn starch. Colloid Surface A 2009, 346, 213-215.

10. Yao, W.R.; Yao, H.Y. Adsorbent characteristics of porous starch. Starch/Starke 2002, 54, 260-263.

11. Gao, F.; Li, D.; Bi, C.H.; Mao, Z.H.; Adhikari, B. Application of various drying methods to produce enzymatically hydrolyzed porous starch granules. Dry Technol. 2013, 31, 13-14. [CrossRef]

12. Chen, Y.S.; Huang, S.R.; Tang, Z.F.; Chen, X.W.; Zhang, Z.F. Structural changes of cassava starch granules hydrolyzed by a mixture of $\alpha$-amylase and glucoamylase. Carbohyd. Polym. 2011, 85, 272-275. [CrossRef]

13. Dura, A.; Błaszczak, W.; Rosell, C.M. Functionality of porous starch obtained by amylase or amyloglucosidase treatments. Carbohyd. Polym. 2014, 101, 837-845. [CrossRef] [PubMed]

14. Chen, G.; Zhang, B. Hydrolysis of granular corn starch with controlled pore size. J. Cereal Sci. 2012, 56, 316-320. [CrossRef]

15. Glenn, G.M.; Klamczynski, A.P.; Woods, D.F.; Chiou, B.; Orts, W.J.; Imam, S.H. Encapsulation of plant oils in porous starch microspheres. J. Agr. Food Chem. 2010, 58, 4180-4184. [CrossRef] [PubMed]

16. Nagata, K.; Okamoto, H.; Danjo, K. Naproxen particle design using porous starch. Drug Dev. Ind. Pharm. 2001, 27, 287-296. [CrossRef] [PubMed]

17. Belingheri, C.; Curti, E.; Ferrillo, A.; Vittadini, E. Evaluation of porous starch as a flavour carrier. Food Funct. 2012, 3, 255-261. [CrossRef] [PubMed]

18. Zeller, B.L.; Saleeb, F.Z.; Ludescher, R.D. Trends in development of porous carbohydrate food ingredients for use in flavor encapsulation. Trends Food Sci. Tech. 1998, 9, 389-394. [CrossRef]

19. Ding, L.; Deng, H.P.; Wu, C.; Han, X. Affecting factors, equilibrium, kinetics and thermodynamics of bromide removal from aqueous solutions by MIEX resin. Chem. Eng. J. 2012, 181-182, 360-370. [CrossRef]

20. Chen, Y.Y.; \& Zhang, D.J. Adsorption kinetics, isotherm and thermodynamics studies of flavones from Vaccinium bracteatum Thunb leaves on NKA-2 resin. Chem. Eng. J. 2014, 254, 579-585. [CrossRef]

21. Chen, H.; Wang, C.; Ye, J.; Zhou, H.; Tao, R.; Li, W. Preparation of starch-hard carbon spherules from ginkgo seeds and their phenol-adsorption characteristics. Molecules 2018, 23, 96. [CrossRef]

22. Qian, W.B.; Lin, X.Q.; Zhou, X.Q.; Chen, X.C.; Xiong, J.; Bai, J.X.; Ying, H.J. Studies of equilibrium, kinetics simulation and thermodynamics of cAMP adsorption onto an anion-exchange resin. Chem. Eng. J. 2010, 165, 907-915. [CrossRef] 
23. Zhang, L.M.; Cai, W.T.; Shan, J.; Zhang, S.; Dong, F. Physical properties and loading capacity of gelatinized granular starches. Ind. Crop Prod. 2014, 53, 323-329. [CrossRef]

24. Baycin, D.; Altiok, E.; Ulkü, S.; Bayraktar, O. Adsorption of olive leaf (Olea europaea L.) antioxidants on silk fibroin. J. Agr. Food Chem. 2007, 55, 1227-1236. [CrossRef]

25. Yoon, S.Y.; Choi, W.J.; Park, J.M.; Yang, J.W. Selective adsorption of flavonoid compounds from the leaf extract of Ginkgo biloba L. Biotechnol. Tech. 1997, 11, 553-556. [CrossRef]

26. Wang, X.M.; Yuan, X.J.; Han, S.; Zha, H.W.; Sun, X.C.; Huang, J.H.; Liu, Y.N. Aniline modified hypercrosslinked polystyrene resins and their adsorption equilibriums, kinetics and dynamics towards salicylic acid from aqueous solutions. Chem. Eng. J. 2013, 233, 124-131. [CrossRef]

27. Ahmaruzzaman, M. Adsorption of phenolic compounds on low-cost adsorbent: A review. Adv. Colloid Interfac. 2008, 143, 48-67. [CrossRef]

28. Lagergren, S. About the theory of so called adsorption of solute substances. Ksver Veterskapsakad Handling 1898, 24, 1-6.

29. Mahmoud, H.R.; Ibrahim, S.M.; El-Molla, S.A. Textile dye removal from aqueous solutions using cheap MgO nanomaterials: Adsorption kinetics, isotherm studies and thermodynamics. Adv. Powder Technol. 2016, 27, 223-231. [CrossRef]

30. Ho, Y.S. Pseudo-second order model for sorption processes. Process Biochem. 1999, 34, 451-465. [CrossRef]

31. Gao, Z.P.; Yu, Z.F.; Yue, T.L.; Quek, S.Y. Adsorption isotherm, thermodynamics and kinetics studies of polyphenols separation from kiwifruit juice using adsorbent resin. J. Food Eng. 2013, 116, 195-201. [CrossRef]

32. Ho, Y.S.; McKay, G. Competitive sorption of copper and nickel ions from aqueous solution using peat. Asorption 1999, 5, 409-417. [CrossRef]

33. Shi, Y.; Kong, X.Z.; Zhang, C.M.; Chen, Y.M.; Hua, Y.F. Adsorption of soy isoflavones by activated carbon: Kinetics, thermodynamics and influence of soy oligosaccharides. Chem. Eng. J. 2013, 215-216, 113-121. [CrossRef]

34. Vasiliu, S.; Bunia, I.; Racovita, S.; Neagu, V. Adsorption of cefotaxime sodium salt on polymer coated ion exchange resin microparticles: Kinetics, equilibrium and thermodynamic studies. Carbohyd. Polym. 2011, 85, 376-387. [CrossRef]

35. Tsai, W.T.; Chang, C.Y.; Ho, C.Y. Adsorption properties and breakthrough model of 1,1-dichloro-1-fluoroethane on activated carbons. J. Hazard Mater. 1999, 69, 53-66. [CrossRef]

36. Malkoc, E.; Nuhoglu, Y. Potential of tea factory waste for chromium (VI) removal from aqueous solutions: Thermodynamic and kinetic studies. Sep. Purif. Technol. 2007, 54, 291-298. [CrossRef]

37. Zhang, H.Y.; Li, A.M.; Sun, J.; Li, P.H. Adsorption of amphoteric aromatic compounds by hyper-cross-linked resins with amino groups and sulfonic groups. Chem. Eng. J. 2013, 217, 354-362. [CrossRef]

38. Weber, T.W.; Chakravorti, R.K. Pore and solid diffusion models for fixed-bed adsorbers. AIChE J. 1974, 20, 228-238. [CrossRef]

39. Sharma, Y.C.; Sinha, A.S.K.; Upadhyay, S.N. Characterization and adsorption studies of Cocos nucifera L. activated carbon for the removal of methylene blue from aqueous solution. J. Chem. Eng. Data 2010, 55, 2662-2667. [CrossRef]

40. Al Othman, Z.A.; Hashem, A.; Habila, M.A. Kinetic, equilibrium and thermodynamic studies of cadmium (II) adsorption by modified agricultural wastes. Molecules 2011, 16, 10443-10456. [CrossRef]

41. Liu, F.; Luo, X.G.; Lin, X.Y. Adsorption of tannin from aqueous solution by deacetylated konjac glucomannan. J. Hazard. Mater. 2010, 178, 844-850. [CrossRef]

42. Oepen, B.V.; Kördel, W.; Klein, W. Sorption of nonpolar and polar compounds to soils: Processes, measurement and experience with the applicability of the modified OECD-Guideline 106. Chemosphere 1991, 22, 285-304. [CrossRef]

43. Zhang, B.; Cui, D.P.; Liu, M.Z.; Gong, H.H.; Huang, Y.J.; Han, F. Corn porous starch: Preparation, characterization and adsorption property. Int. J. Biol. Macromol. 2012, 50, 250-256. [CrossRef]

44. Wu, Y.; Du, X.F.; Ge, H.H.; Lv, Z. Preparation of microporous starch by glucoamylase and ultrasound. Starch/Stärke 2011, 63, 217-225. [CrossRef]

45. O'Brien, S.; Wang, Y.J. Susceptibility of annealed starches to hydrolysis by alpha-amylase and glucoamylase. Carbohyd. Polym. 2008, 72, 597-607. [CrossRef]

46. Jiang, S.W.; Yu, Z.Y.; Hu, H.L.; Lv, J.; Wang, H.L.; Jiang, S.T. Adsorption of procyanidins onto chitosan-modified porous rice starch. LWT-Food Sci. Technol. 2017, 84, 10-17. [CrossRef] 
47. Singleton, V.L.; Rossi, J.A. Colorimetry of total phenolics with phosphomolybdic-phosphotungstic acid reagents. Am. J. Enol. Viticult. 1965, 16, 144-158.

48. Anesini, G.; Ferraro, G.E.; Filip, R. Total polyphenol content and antioxidant capacity of commercially available tea (Camellia sinensis) in Argentina. J. Agr. Food Chem. 2008, 56, 9225-9229. [CrossRef]

49. Monsanto, M.; Mestrom, R.; Zondervan, E.; Bongers, P.; Meuldijk, J. Solvent swing adsorption for the recovery of polyphenols from black tea. Ind. Eng. Chem. Res. 2015, 54, 434-442. [CrossRef]

Sample Availability: Samples of the compounds microporous starch are available from the authors.

(C) 2019 by the authors. Licensee MDPI, Basel, Switzerland. This article is an open access article distributed under the terms and conditions of the Creative Commons Attribution (CC BY) license (http://creativecommons.org/licenses/by/4.0/). 